\title{
Vasopressin ameliorates
}

Korean Journal of Anesthesiology

hypotension induced by beach

chair positioning in a dosedependent manner in patients undergoing arthroscopic shoulder surgery under general anesthesia

\author{
Soo Young Cho, Joungmin Kim, Sun Hong Park, Seongtae Jeong, \\ Sung-Su Chung, and Kyung Yeon Yoo \\ Department of Anesthesiology and Pain Medicine, Chonnam National University Medical School, Gwangju, Korea
}

\begin{abstract}
Background: The beach chair position (BCP) is associated with hypotension that may lead to cerebral ischemia. Arginine vasopressin (AVP), a potent vasoconstrictor, has been shown to prevent hypotension in BCP. It also improves cerebral oxygenation in different animal models. The present study examined the effect of escalating doses of AVP on systemic hemodynamics and cerebral oxygenation during surgery in BCP under general anesthesia.

Methods: Sixty patients undergoing arthroscopic shoulder surgery in BCP under general anesthesia were randomly allocated to receive either saline (control, $\mathrm{n}=15)$ or three different doses of AVP $(0.025,0.05$, or $0.075 \mathrm{U} / \mathrm{kg} ; \mathrm{n}=15$ each) 2 minutes before $\mathrm{BCP}$. Mean arterial pressure (MAP), heart rate (HR), regional cerebral oxygen saturation $\left(\mathrm{SctO}_{2}\right)$, and jugular venous oxygen saturation $\left(\mathrm{SjvO}_{2}\right)$ were measured after induction of anesthesia and before (presitting in supine position) and after BCP.

Results: AVP per se given before $\mathrm{BCP}$ increased MAP, and decreased $\mathrm{SjvO}_{2}, \mathrm{SctO}_{2}$, and $\mathrm{HR}$ in all patients $(\mathrm{P}<0.05$ for all). BCP decreased MAP, the magnitude of which and hence the incidence of hypotension was decreased by AVP in a dose-dependent manner. While in BCP, every dose of AVP reduced the $\mathrm{HR}$ and $\mathrm{SctO}_{2}$. Accordingly, it increased the incidence of cerebral desaturation ( $>20 \% \mathrm{SctO}_{2}$ decrease from the baseline value) with no differences in $\mathrm{SjvO}_{2}$ and the incidence of $\mathrm{SjvO}_{2}<50 \%$ or $\mathrm{SjvO}_{2}<40 \%$ among the groups.

Conclusions: AVP ameliorates hypotension associated with BCP in a dose-dependent manner in patients undergoing shoulder surgery under general anesthesia. However, AVP may have negative effects on $\mathrm{SctO}_{2}$ before and after $\mathrm{BCP}$ and on $\mathrm{SjvO}_{2}$ before BCP.
\end{abstract}

Key Words: Arginine vasopressin, Beach chair position, Jugular venous oxygen saturation, Regional cerebral oxygen saturation.

Corresponding author: Kyung Yeon Yoo, M.D., Ph.D.

Department of Anesthesiology and Pain Medicine, Chonnam National University Medical School, 42, Jebong-ro, Dong-gu, Gwangju 501-757, Korea Tel: 82-62-220-6895, Fax: 82-62-232-6293

E-mail: kyyoo@jnu.ac.kr

This is a thesis for a Doctor's degree by Soo Young Cho.

Received: December 15, 2014.

Revised: 1st, January 7, 2015; 2nd, January 15, 2015.

Accepted: January 16, 2015.

Korean J Anesthesiol 2015 June 68(3): 232-240

http://dx.doi.org/10.4097/kjae.2015.68.3.232

\section{Introduction}

The beach chair position (BCP) is commonly used in many institutions for patients undergoing arthroscopic shoulder surgery [1]. However, besides the increased risk of air embolism, the position is often associated with hemodynamic instability which may lead to cerebral hypoperfusion and catastrophic neurological outcomes [2]. Brain and spinal cord ischemia [3], transient visual loss, ophthalmoplegia, and acute hemiplegia [4] have been documented following surgery in BCP.

(c) This is an open-access article distributed under the terms of the Creative Commons Attribution Non-Commercial License (http://creativecommons.org/ licenses/by-nc/4.0/), which permits unrestricted non-commercial use, distribution, and reproduction in any medium, provided the original work is properly cited. 
Hypotension occurring in response to anesthesia or postural changes under general anesthesia is usually treated by ephedrine or phenylephrine. However, their duration of action is relatively short, often requiring repetitive administration to raise the blood pressure $[5,6]$. Moreover, phenylephrine reduces frontal lobe oxygenation as measured using near-infrared spectroscopy (NIRS) as opposed to ephedrine [7]. A possible concern about cerebral vasoconstriction and consequently reduced cerebral blood flow ( $\mathrm{CBF}$ ) has been raised after the use of a-agonists such as phenylephrine or norepinephrine.

Arginine vasopressin (AVP), a potent vasoconstrictor, is being increasingly used to counteract hypotension in the perioperative setting $[8,9]$. It improves CBF and cerebral oxygen delivery in different animal models [10,11], although its effect on cerebral oxygenation is controversial. Hypotension occurring in patients who change from the supine position to the BCP may persist for up to $30 \mathrm{~min}$ [2], while the pressor effect of AVP lasts for about $30 \mathrm{~min}$ and it has a plasma half-life of 10-20 min [9]. Therefore, AVP may be an attractive vasopressor to counteract hypotension associated with BCP.

Indeed, a recent study demonstrated that AVP prevented BCP-induced hypotension and hence reduced the requirement of vasopressors in patients undergoing arthroscopic shoulder surgery under general anesthesia [12]. The use of AVP, however, was associated with reduction infrontal lobe oxygenation $\left(\mathrm{SctO}_{2}\right)$ as measured by NIRS and reduction in jugular venous oxygen saturation $\left(\mathrm{SjvO}_{2}\right)$ [12], suggesting a concomitant reduction in the CBF probably due to cerebral vasoconstriction.

Different doses of AVP may yield different hemodynamic and cerebral oxygenation effects. However, a dose-effect relationship has not been determined with respect to the effect of AVP on MAP, jugular venous desaturation, or NIRS-determined cerebral desaturation. The present study aimed to determine the effects of escalating doses of AVP on MAP, $\mathrm{SjvO}_{2}$, and $\mathrm{SctO}_{2}$ in patients undergoing arthroscopic shoulder surgery under general anesthesia. Jugular venous oxygen saturation was measured by using jugular venous oximetry, and regional cerebral oxygen saturation was measured by using NIRS.

\section{Materials and Methods}

Following approval by the Institutional Ethics Committee, written informed consents were obtained from 60 patients scheduled to undergo elective arthroscopic shoulder surgery in BCP under general anesthesia. Exclusion criteria included preexisting neurological diseases, age $<18$ years, American Society of Anesthesiologists physical status IV or V, myocardial ischemia, and refusal to participate in the study. The patients were assigned to receive either saline (control, $\mathrm{n}=15$ ) or one of the three AVP doses $(0.025,0.05,0.075 \mathrm{U} / \mathrm{kg} ; \mathrm{n}=15$ each$)$ based on a comput- er-generated randomization list.

All patients received premedication (midazolam $0.1 \mathrm{mg} / \mathrm{kg}$ ) and their usual medications orally one hour before being transported to the operating room, with the exception of angiotensinconverting enzyme inhibitors (ACEIs) or angiotensin II receptor antagonists (AIIRAs), which were discontinued on the day of surgery. After wrapping the lower limbs with support stockings, an intravenous (IV) cannula was inserted into the antecubital vein and lactated Ringer's solution $10 \mathrm{ml} / \mathrm{kg}$, followed by an infusion at the rate of $10 \mathrm{ml} / \mathrm{kg} / \mathrm{h}$, was administered before patients assumed the sitting position. Upon arrival in the operating room, a 20-gauge catheter was inserted into the radial artery to monitor blood pressure and to take blood samples. The pressure transducer was placed at the mid-axillary level when patients were in the supine position, and it was placed at the external ear canal level when patients were in BCP [13]. A standard Bispectral Index (BIS) ${ }^{\circledR}$ electrode montage (Aspect Medical Systems, Natick, MA, USA) was applied on the left forehead before induction of anesthesia, and BIS was measured continuously using an Aspect BIS ${ }^{\circledR}$ A-2000 monitor version 3.31 (Aspect Medical Systems). Frontal lobe $\mathrm{SctO}_{2}$ was monitored by NIRS with an INVOS $^{\circledR} 5100 B$ cerebral oximeter (Somanetics, Troy, MI, USA).

A standardized induction technique was performed: after full preoxygenation, anesthesia was induced with an effect-site target-controlled infusion (TCI) of propofol and remifentanil. After IV administration of rocuronium $0.8 \mathrm{mg} / \mathrm{kg}$, the trachea was intubated and the lungs were mechanically ventilated with $50 \%$ oxygen-air adjusted to maintain the end-tidal carbon dioxide tension between 35 and $40 \mathrm{mmHg}$. TCI effect-site concentrations of propofol were also adjusted to achieve a BIS reading of 40-50, and the concentrations of remifentanil were adjusted to maintain MAP within $20 \%$ of the preinduction value. Propofol and remifentanil were used in this study to maintain general anesthesia because they preserve cerebral autoregulation [14], cerebrovascular carbon dioxide reactivity [15], and CBF-cerebral metabolic rate of oxygen coupling [16], and they do not possess an intrinsic cerebral vasodilating effect, which may occur with inhalation anesthetic agents [17].

Standard monitoring was used throughout the procedure, including electrocardiography, invasive arterial monitoring, pulse oximetry, capnography, BIS monitoring, and measurement of core temperature via an esophageal probe. Neuromuscular blockade was carefully controlled by train-of-four monitoring, and additional boluses of rocuronium (10 mg boluses) were administered to maintain one twitch response during the surgical procedure. For continuous monitoring of $\mathrm{SjvO}_{2}$ and blood sampling, a central venous oximetry catheter (PreSep ${ }^{\mathrm{TM}}$ Oximetry Catheter; Edwards Lifesciences, Irvine, CA, USA) connected to the Vigileo ${ }^{\mathrm{TM}}$ monitor (Edwards Lifesciences) was positioned by using the Seldinger technique under direct ultrasound visualiza- 
tion so that the tip was in the jugular bulb contralateral to the side of surgery.

Approximately $20 \mathrm{~min}$ after anesthesia induction, when hemodynamics became stable, the head was secured in a neutral position to ensure that cerebral venous drainage was not impaired, and one of the three AVP doses (Pitressin, Parke-Davis, USA) or an equal volume of saline (controls) was given as an IV bolus over $20 \mathrm{sec}$. Beach-chair positioning at $65-75^{\circ}$ from the horizontal plane was achieved with the use of a dedicated beach-chair table. The dose of AVP was chosen based on the earlier study which used an IV bolus of $0.07 \mathrm{U} / \mathrm{kg}$ to prevent hypotension in BCP surgery [12]. TCI effect-site concentrations of propofol and remifentanil were achieved using a TCI device. The surgery began approximately $20 \mathrm{~min}$ after positioning when hemodynamics had become stable.

MAP and HR were recorded before induction of anesthesia. Simultaneously, peripheral arterial oxygen saturation $\left(\mathrm{SpO}_{2}\right)$, $\mathrm{SctO}_{2}$, and BIS values were measured in patients while breathing room air. These variables (MAP, HR, BIS, and $\mathrm{SctO}_{2}$ ) and $\mathrm{SjvO}_{2}$ were recorded before administration of the study drug (postinduction, baseline values), before (presitting in supine position) and every min after sitting position for $15 \mathrm{~min}$, and then every $5 \mathrm{~min}$ for another $15 \mathrm{~min}$. The magnitudes of maximum changes in $\mathrm{SjvO}_{2}$ after positioning were determined by calculating the differences between $\mathrm{SjvO}_{2}$ measured after induction of anesthesia (baseline) and the lowest $\mathrm{SjvO}_{2}$ value observed within $15 \mathrm{~min}$ after the positioning. Jugular bulb oxygen desaturation was defined as a $\mathrm{SjvO}_{2}$ value of less than $50 \%$ lasting $>5 \mathrm{~min}$ under conditions of normal catheter light intensity [18], and cerebral oxygen desaturation was defined as a decline in $\mathrm{SctO}_{2}$ more than $20 \%$ from post-induction baseline values for $>15 \mathrm{sec}$ [19]. A fall in $\mathrm{SctO}_{2}$ of greater than $20 \%$ following clamping in patients undergoing carotid endarterectomy surgery is known to be associated in most patients with marked deterioration in cerebral function [19]. Hypotension was defined as MAP less than $50 \mathrm{mmHg}$, measured at the level of the external auditory canal. When hypotension occurred, it was treated with a bolus of ephedrine $(8 \mathrm{mg})$ or phenylephrine $(100 \mu \mathrm{g})$ and rapid fluid infusion. Vasopressor therapy was repeated every 2 min if hypotension persisted or recurred. The number and duration of episodes of cerebral and jugular bulb oxygen desaturation and hypotension and the total dose of ephedrine or phenylephrine were recorded. Upon completion of the surgery, the anesthetic was discontinued, and residual neuromuscular block was antagonized with pyridostigmine $15 \mathrm{mg}$ and glycopyrrolate $0.4 \mathrm{mg}$. Estimated blood loss and amount of fluid or blood administered during the surgery were recorded. At a postoperative visit on the evening of surgery, the patient was assessed neurologically by gross motor and sensory neurological evaluation and gross cognitive evaluation.

\section{Statistical analysis}

Using the Cochran-Armitage test for trend in proportions, a sample size of 12 patients per group was determined based on four groups with AVP dosage values of 0, 0.025, 0.05, and 0.075 $\mathrm{U} / \mathrm{kg}$ and proportions of hypotension equal to $0.6,0.4,0.25$, and 0.1 , respectively. Our calculations indicated that a total sample size of 48 subjects would give $90 \%$ power to detect a linear trend using a two-sided Z-test with continuity correction and a significance level of 0.05 (TrialSize package in $\mathrm{R}$ software version 3.1.2.). Taking into account possible dropouts, about 15 patients were recruited in each group.

Data are expressed as number or mean \pm SD. They were analyzed using StatView software version 4.0 (Abacus Concepts Inc., Berkeley, CA, USA). The patient characteristics and complication rates were compared among groups using one-way analysis of variance (ANOVA) or the $\chi 2$ test. Serial changes in cardiovascular, $\mathrm{SctO}_{2}$, and $\mathrm{SjvO}_{2}$ data were analyzed using the 2-way repeated measures ANOVA, with time as a within-group factor, group (saline/AVP) as a between-factors measure, and an interaction between time and group. Dunnett's $t$ test was used for multiple pairwise comparisons when a significant difference was indicated. Normal distribution of continuous variables was determined using the Kolmogorov-Smirnov test (all P values > 0.05).

\section{Results}

Seventy-one patients undergoing arthroscopic shoulder surgery under general anesthesia were assessed for eligibility to enroll the study. Fig. 1 shows the CONSORT flow chart illustrating patient recruitment. Data analysis was performed in 4 groups comprising 60 patients. Demographic and intraoperative data did not differ among the groups (Table 1). Nor did total sitting time, intraoperative fluid requirement, and amount of blood loss differ among the groups.

Table 2 shows preoperative hemodynamics and peripheral oxygen saturation, and intraoperative blood gas data. These parameters did not differ significantly among the groups. Effectsite TCI concentrations of propofol ranged between $1.5 \mu \mathrm{g} / \mathrm{ml}$ and $4.0 \mu \mathrm{g} / \mathrm{ml}$, and those of remifentanil ranged between $0.5 \mathrm{ng} /$ $\mathrm{ml}$ and $6.0 \mathrm{ng} / \mathrm{ml}$. No gross neurological or cognitive deficits were identified postoperatively in any group.

Hemodynamic data after induction of anesthesia, and before (presitting value) and after BCP are depicted in Fig. 2. After anesthetic induction, MAP decreased significantly $(\mathrm{P}<0.05)$ with no significant alterations in HR in each group. AVP increased MAP by $20-36 \%(\mathrm{P}<0.0001)$ in a dose-dependent manner and decreased HR by $10-14 \%(\mathrm{P}<0.05)$. When positioned sitting upright, MAP decreased in each group, although the magnitude of decrease was less with administration of larger AVP doses 


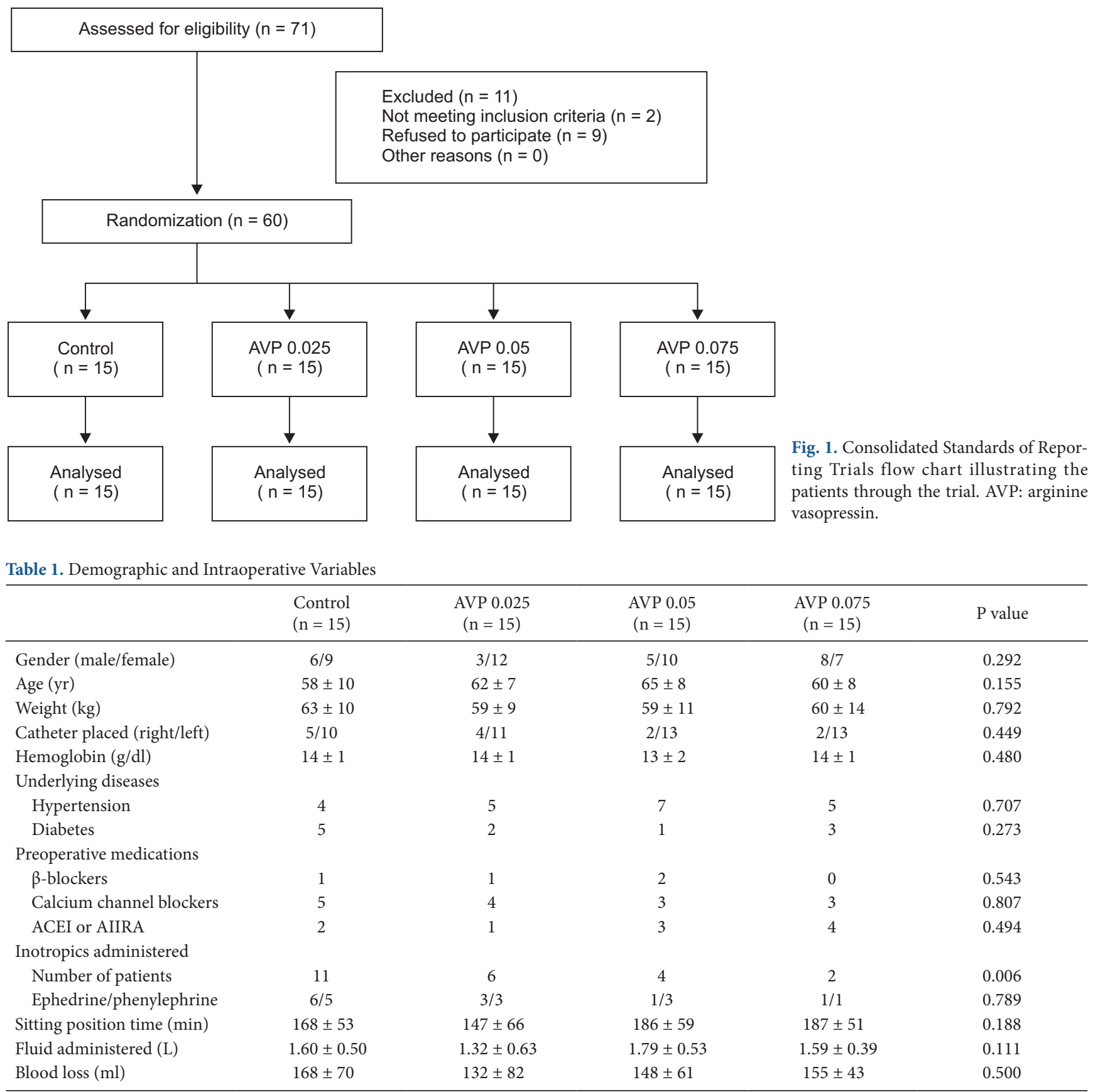

Data are mean \pm SD or numbers. AVP: arginine vasopressin, ACEI: angiotensin converting enzyme inhibitor, AIIRA: angiotensin II receptor antagonist.

Table 2. Preoperative Hemodynamic and Intraoperative Arterial Blood Gas Data

\begin{tabular}{|c|c|c|c|c|c|}
\hline & $\begin{array}{l}\text { Control } \\
(\mathrm{n}=15)\end{array}$ & $\begin{array}{c}\text { AVP } 0.025 \\
(\mathrm{n}=15)\end{array}$ & $\begin{array}{c}\text { AVP } 0.05 \\
(\mathrm{n}=15)\end{array}$ & $\begin{array}{c}\text { AVP } 0.075 \\
(\mathrm{n}=15)\end{array}$ & $P$ value \\
\hline Mean arterial pressure $(\mathrm{mmHg})$ & $101 \pm 11$ & $102 \pm 13$ & $105 \pm 11$ & $105 \pm 13$ & 0.699 \\
\hline Heart rate (beats/min) & $66 \pm 15$ & $67 \pm 11$ & $68 \pm 12$ & $65 \pm 9$ & 0.921 \\
\hline $\mathrm{SpO}_{2}(\%)$ & $97 \pm 2$ & $97 \pm 2$ & $97 \pm 2$ & $97 \pm 2$ & 0.640 \\
\hline $\mathrm{SctO}_{2}(\%)$ & $67 \pm 4$ & $69 \pm 6$ & $66 \pm 6$ & $69 \pm 8$ & 0.414 \\
\hline $\mathrm{PaCO}_{2}(\mathrm{mmHg})$ & $40 \pm 3$ & $40 \pm 5$ & $38 \pm 2$ & $38 \pm 3$ & 0.272 \\
\hline
\end{tabular}

Data are mean \pm SD or numbers. AVP: arginine vasopressin, $\mathrm{SpO}_{2}$ : peripheral arterial saturation of oxygen, $\mathrm{SctO} \mathrm{O}_{2}$ : regional cerebral tissue oxygen saturation, $\mathrm{PaCO}_{2}$ : arterial partial pressure of carbon dioxide. 
A

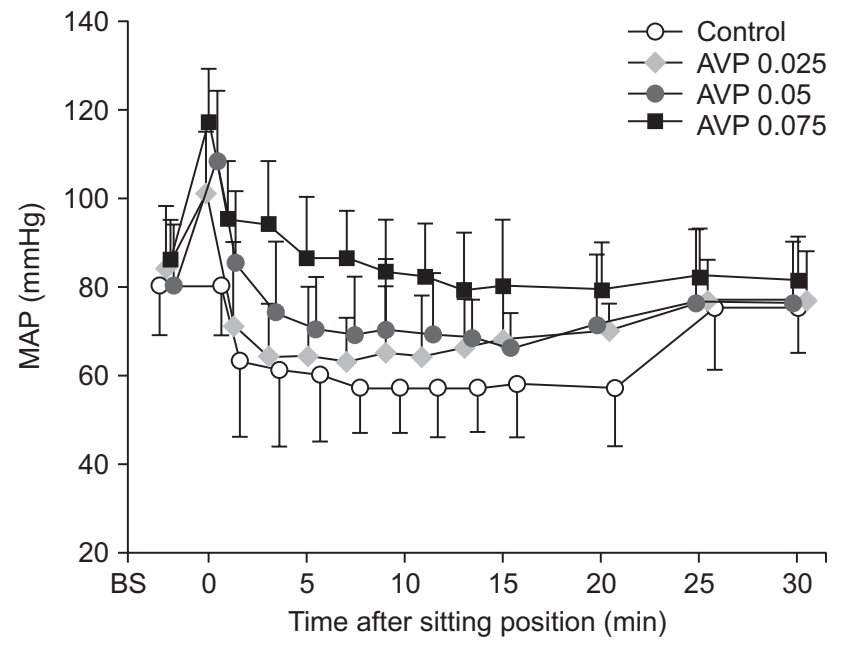

B

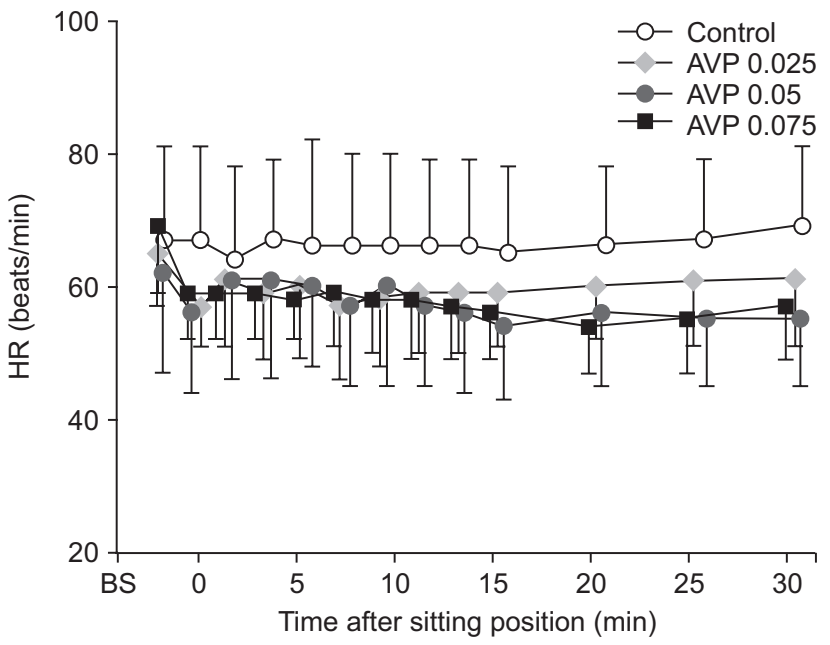

Fig. 2. Mean arterial pressure (MAP, A) and heart rate (HR, B) after moving to the beach chair position in the patients who were given saline (control) or arginine vasopressin (AVP) 0.025 (AVP 0.025), 0.05 (AVP 0.05) or $0.075 \mathrm{U} / \mathrm{kg}$ (AVP 0.075) under general anesthesia. Values are means \pm SD. BS $=$ after induction of anesthesia. Presitting values after saline or AVP administration in the supine position are shown at time 0 . MAP was significantly higher from presitting to $20 \mathrm{~min}$ into BCP $(\mathrm{P}<0.0001)$ in the AVP 0.05 and AVP 0.075 groups, and at presitting and from $13 \mathrm{~min}$ to $20 \mathrm{~min}(\mathrm{P}<0.05)$ into BCP in the AVP 0.025 group, and HR was significantly slower from 13 minutes into BCP to the end of study in the AVP 0.05 and AVP 0.075 groups than in the control group $(\mathrm{P}<0.05)$.

(2-way ANOVA: significant main effect of time [P $<0.0001]$, significant main effect of group $[\mathrm{P}<0.001]$, and significant interaction between time and group $[\mathrm{P}<0.0001]$ in the AVP 0.075 and AVP 0.05 groups; significant main effect of time [P $<0.0001]$, significant main effect of group $[\mathrm{P}=0.017]$, and no significant interaction between time and group $[\mathrm{P}=0.079]$ in the AVP 0.025 group; Fig. 2A). In addition, an earlier onset (within 5 min vs. after $5 \mathrm{~min}$ in $\mathrm{BCP}$ ) and more frequent episodes of hypotension which needed vasopressors were noted in the control group than in the AVP groups.

Although HR remained unaltered in the control group, it was progressively decreased by BCP in each AVP-treated group (2-way ANOVA: significant main effect of time [P $<0.0001]$, significant main effect of group $[P=0.0395]$, and significant interaction between time and group $[\mathrm{P}<0.0001]$ in the AVP 0.075 group; significant main effect of time $[\mathrm{P}=0.0226]$, no significant main effect of group $[\mathrm{P}=0.0673]$, and significant interaction between time and group $[\mathrm{P}=0.0031]$ in the AVP 0.05 group; significant main effect of time $[\mathrm{P}=0.0296]$, no significant main effect of group [P $=0.0958]$, and no significant interaction between time and group $[\mathrm{P}=0.1909]$ in the AVP 0.025 group; Fig. 2B).

Fig. 3 shows $\mathrm{SjvO}_{2}$ values after induction of anesthesia, and before and after BCP. Before AVP administration, $\mathrm{SjvO}_{2}$ (postinduction baseline) values were similar among the groups. $\mathrm{SjvO}_{2}$ values decreased by $3.7 \pm 4.3 \%, 6.5 \pm 5.0 \%$, and $8.9 \pm 3.5 \%$ after AVP administration in the AVP 0.025, AVP 0.05, and AVP 0.075

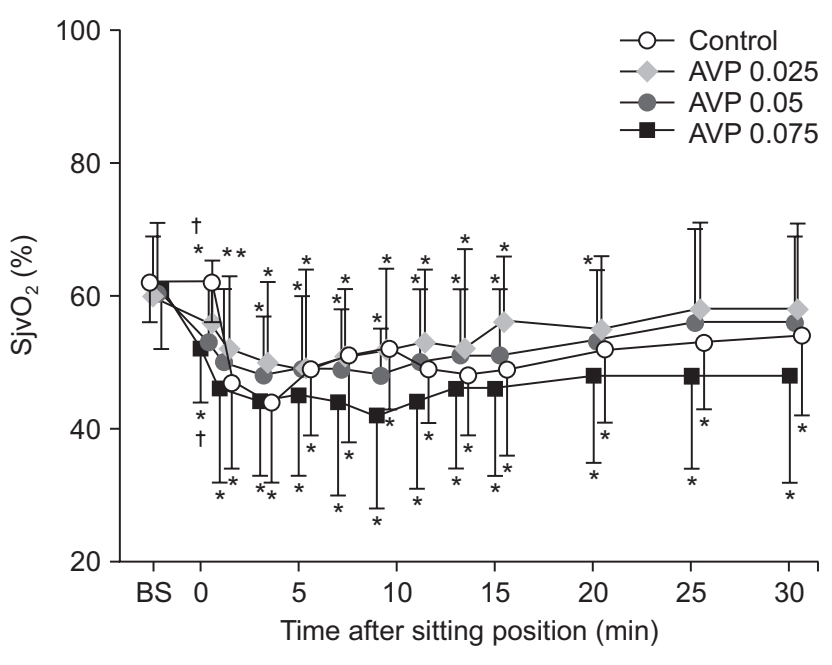

Fig. 3. Jugular venous oxygen saturation $\left(\mathrm{SjvO}_{2}\right)$ after moving to the beach chair position in patients given saline (control) or arginine vasopressin (AVP) 0.025 (AVP 0.025), 0.05 (AVP 0.05), or $0.075 \mathrm{U} /$ $\mathrm{kg}$ (AVP 0.075) under general anesthesia. Values are means \pm SD. BS $=$ after induction of anesthesia. Presitting values after saline or AVP administration in the supine position are shown at time $0 . * \mathrm{P}<0.05$ vs. postinduction baseline values; ${ }^{\dagger} \mathrm{P}<0.05$ vs. the control group. There was a significant decrease in $\mathrm{SjvO}_{2}$ after AVP and a further decrease after the positioning in all groups. However, among the 4 groups, there was no significant difference at any time point during the experiment except for significantly lower $\mathrm{SjvO}_{2}$ values at presitting in the AVP 0.05 and AVP 0.075 groups compared with the control group. 


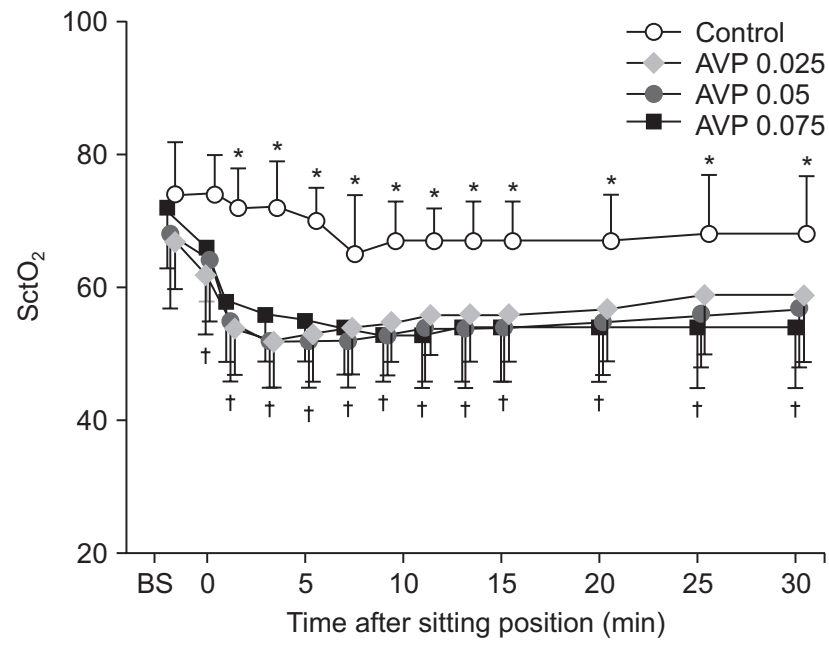

Fig. 4. Regional cerebral tissue oxygen saturation $\left(\mathrm{SctO}_{2}\right)$ after moving to the beach chair position in patients who were given saline (control) or arginine vasopressin (AVP) 0.025 (AVP 0.025), 0.05 (AVP 0.05), or $0.075 \mathrm{U} / \mathrm{kg}$ (AVP 0.075) under general anesthesia. Values are means \pm $\mathrm{SD} . \mathrm{BS}=$ after induction of anesthesia. Presitting values after saline or AVP administration in the supine position are shown at time $0 .{ }^{*} \mathrm{P}<0.05$ vs. postinduction baseline values; ${ }^{\dagger} \mathrm{P}<0.05$ vs. postinduction baseline values and the control group at the same time. There was a significant decrease in $\mathrm{SctO}_{2}$ after AVP and a further decrease after the positioning in all AVP-treated groups. $\mathrm{SctO}_{2}$ was significantly lower in all AVP-treated groups than in the control group from the presitting value $(t=0)$ to the end of experiment. However, among the $3 \mathrm{AVP}$-treated groups, $\mathrm{SctO}_{2}$ was not significantly different at any time point during the experiment.

groups, respectively $(\mathrm{P}<0.0001$ for all). While in $\mathrm{BCP}$, they decreased less from presitting values in the AVP-treated groups than in the control group $(13-15 \%$ vs. $\sim 23 \%, \mathrm{P}=0.0004)$. The magnitude of maximum decreases in $\mathrm{SjvO}_{2}$ in $\mathrm{BCP}(17-24 \%)$ was comparable among the groups $(\mathrm{P}=0.065)$. Two-way ANOVA revealed no significant effects of AVP on $\mathrm{SjvO}_{2}$ in any AVPtreated groups $(\mathrm{P}=0.219)$.

Fig. 4 shows $\mathrm{SctO}_{2}$ values after induction of anesthesia, and before and after BCP. They were similar before $(\mathrm{P}=0.414)$ and after (post-induction, baseline) $(\mathrm{P}=0.172)$ induction of anesthesia. They decreased by $6-9 \%$ following the administration of AVP $(\mathrm{P}<0.01)$ and were further decreased by $\mathrm{BCP}$ in all AVPtreated groups $(\mathrm{P}<0.0001)$. They were also decreased by $\mathrm{BCP}$ in the control group $(\mathrm{P}<0.0001)$. Two-way ANOVA showed a significant effect of $\mathrm{AVP}$ on $\mathrm{SctO}_{2}$ in all AVP-treated groups $(\mathrm{P}<$ 0.0001 for all) without inter-group differences.

The adverse effects are shown in Fig. 5. Hypotension (MAP < $50 \mathrm{mmHg}$ ) occurred and vasopressors were used less frequently after larger AVP doses. However, the incidence of cerebral desaturation $\left(>20 \%\right.$ decrease in $\mathrm{SctO}_{2}$ from post-induction baseline values) was higher in the AVP-treated groups than in the control group $(\mathrm{P}<0001)$. The incidence of $\mathrm{SjvO}_{2}<50 \%(60-73 \%$, $\mathrm{P}=0.896)$ and $\mathrm{SjvO}_{2}<40 \%(20-50 \%, \mathrm{P}=0.160)$ did not differ among the groups.

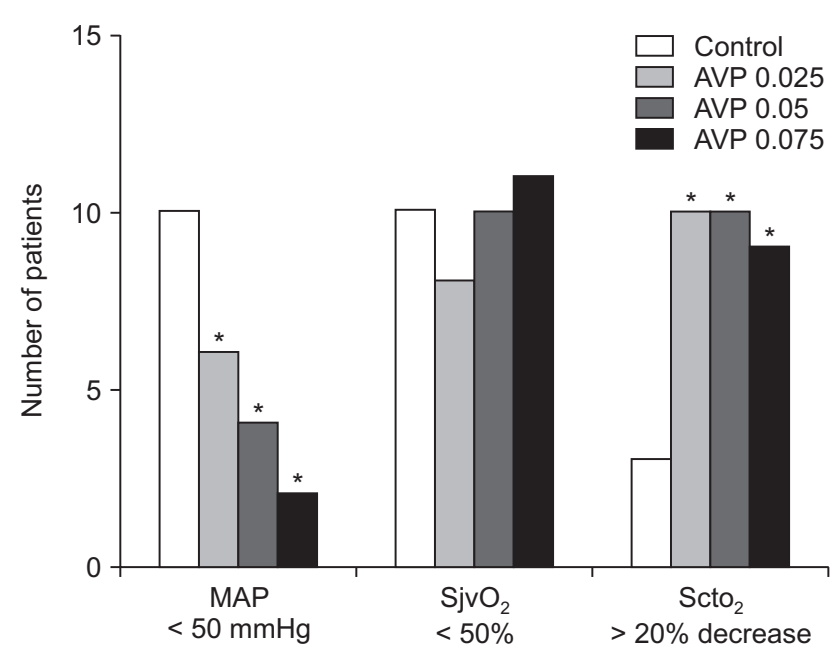

Fig. 5. The incidences of hypotension (mean arterial pressure [MAP] of less than $50 \mathrm{mmHg}$ ), jugular venous oxygen desaturation $\left(\mathrm{SjvO}_{2}\right.$ less than $50 \%$ ), and cerebral oxygen desaturation (more than $20 \%$ decrease in $\mathrm{SctO}_{2}$ from baseline) after moving to the beach chair position in patients who were given saline (control) or arginine vasopressin (AVP) 0.025 (AVP 0.025), 0.05 (AVP 0.05), or $0.075 \mathrm{U} / \mathrm{kg}$ (AVP 0.075) under general anesthesia. ${ }^{*} \mathrm{P}<0.05$ vs. the control group.

\section{Discussion}

The present study demonstrated that a prophylactic bolus dose of AVP ameliorates hypotension in BCP in a dose-dependent manner. However, there were significant reductions in NIRS-determined cerebral oxygenation after the use of AVP. In addition, AVP per se decreased $\mathrm{SjvO}_{2}$, as has been previously observed [12]. $\mathrm{SjvO}_{2}$ reflects the balance between the brain oxygen supply and consumption, and reduction in $\mathrm{SjvO}_{2}$ may represent a decrease in the CBF.

AVP per se administered just prior to taking BCP reduced $\mathrm{SjvO}_{2}$ dose-dependently in the present study. This finding is consistent with that in the study by Bein et al. [20], who reported that AVP negatively affected cerebral oxygenation as measured by NIRS despite an elevation of systemic blood pressure in the swine with an intact systemic circulation under propofol anesthesia. They also noted that the reduced indices of cerebral oxygenation and cerebral blood volume after AVP did not return to their baseline values until the end of the study, suggesting a sustained cerebral vasoconstriction and reduced CBF. Fernández et al. [21] demonstrated generalized cerebral vasoconstriction following AVP injection into the cerebral circulation in conscious goats. The cerebral pressure autoregulation challenged by vasopressors (phenylephrine or norepinephrine) was preserved under propofol anesthesia, which was used in the present study, but not under volatile anesthesia [22]. The cerebral vasculature may have been constricted directly and indirectly by AVP, and hence the $\mathrm{CBF}$ reduced to such an extent that it affected $\mathrm{SjvO}_{2}$. 
In contrast, AVP did not affect $\mathrm{SjvO}_{2}$ in BCP in any AVPtreated groups in the present study, as has been previously observed [12]. When systemic hemodynamics are unstable, such as in cardiopulmonary resuscitation [10] or in severe polytrauma [11], AVP shows favorable results. When the blood pressure is below the lower limit of cerebral autoregulation, AVP-induced increases in blood pressure would enhance the CBF and cerebral oxygenation due to a pressure-passive effect. AVP would predominantly raise the systemic vascular resistance and shift blood to the brain even in BCP. Moreover, AVP was shown to cause vasodilationof a cerebral artery via release of nitric oxide through activation of $\mathrm{V} 1$ receptors despite systemic vasoconstriction [23]. It is likely that the effect of AVP on cerebral oxygenation varies as a function of an individual's physiologic state. A bolus of AVP may impair cerebral oxygenation during stable hemodynamic conditions, while it may improve cerebral oxygenation in circumstances where systemic hemodynamics and cerebral perfusion has already been inadequate or abruptly compromised such as when rapid surgical positioning impedes the $\mathrm{CBF}$.

On the other hand, the use of AVP was associated with significantly lower $\mathrm{SctO}_{2}$ and higher incidence of cerebral desaturation (> 20\% decrease in $\mathrm{SctO}_{2}$ from postinduction values) in BCP. It has been known that NIRS accuracy might suffer from contamination of the signal by extra-cranial signals from the scalp, which can suffer marked vasoconstriction induced by systemically-acting agents $[24,25]$. The vasoconstrictive effects of AVP may vary in different vascular beds, with the greatest vasoconstriction being observed in cutaneous vessels [9,11]. In addition, cerebral oximetry is also affected by the relative composition of arterial and venous blood assessed in each position when a potent vasopressor such as phenylephrine or norepinephrine is administered [26,27]. In this context, the reduction in $\mathrm{SctO}_{2}$ after the use of AVP may, in part, be accounted for by reduced extracerebral tissue blood flow (i.e., cutaneous vasoconstriction) [9] and/or reduced cerebral arterial/venous volume ratio rather than by reduced $\mathrm{CBF}$ which may give rise to changes in $\mathrm{SctO}_{2}$ with no alterations in $\mathrm{SjvO}_{2}$. Indeed, the reduction in $\mathrm{SctO}_{2}$ by using phenylephrine can be mainly due to the major contribution of skin perfusion to the NIRS signal rather than due to actual changes in the CBF $[28,29]$.

It has been reported that, in patients undergoing shoulder surgery in BCP under general anesthesia, preoperative use of antihypertensives such as renin-angiotensin system (RAS) inhibitors is associated with an increased incidence of intraoperative hypotension [6]. AVP has been proposed as the pressor of choice in the treatment of refractory hypotension in patients taking RAS inhibitors, since it acts on the third vasopressor system; while the sympathetic nervous system and the RAS are respectively blunted by general anesthesia and ACEIs or AIIRAs $[8,30]$. In the present study, among the 10 patients taking RAS inhibitors, 2 patients (100\%) in the control group, the single patient (100\%) in the AVP 0.025 group, and 2 (67\%) of the 3 patients in the AVP 0.05 group but none $(0 \%)$ of the 4 patients in the AVP 0.075 group developed hypotension upon upright positioning; thus justifying the use of the highest dose of AVP for preventing the development of hypotension after shifting to BCP.

$\mathrm{SjvO}_{2}$ less than $50 \%$ is indicative of cerebral hypoperfusion, and $\mathrm{SjvO}_{2}$ less than $40 \%$ may be related to cerebral ischemia [18]. In the present study, AVP given just before BCP dose-dependently decreased $\mathrm{SjvO}_{2}$, suggesting that AVP decreased the CBF via possible cerebral vasoconstriction to such an extent that it affected $\mathrm{SjvO}_{2}$. $\mathrm{SjvO}_{2}$ was further decreased by BCP in all AVPtreated groups, showing an apparent jugular desaturation $\left[\mathrm{SjvO}_{2}\right.$ $<50 \%$ (60-73\%); $\mathrm{SjvO}_{2}<40 \%$ (20-50\%)] in the first 15 minutes after BCP with no inter-group differences. Moreover, most of the AVP-treated patients (60-67\%) experienced NIRS-determined cerebral desaturation. Other adverse effects of AVP reported in humans include mesenteric ischemia, myocardial ischemia, skin necrosis, and digital ischemia [9]. Although none of the patients suffered from a clinically-significant cerebral injury, a routine use of AVP to increase cerebral perfusion pressure in BCP should be cautious until adequate and well-controlled studies prove its safety and efficacy in a larger population.

The current study has several limitations. First, all patients were free from cerebral pathology. It is unclear how $\mathrm{SjvO}_{2}$ and $\mathrm{SctO}_{2}$ would have responded after shifting to BCP in patients with cerebrovascular disease or increased intracranial pressure. Second, although most patients have dominant right-sided drainage for the jugular vein, the $\mathrm{SjvO}_{2}$ catheter was inserted into the contralateral side of surgery without examination of the drainage system by angiography in each patient. The lack of catheterization in the dominant drainage system may have affected the results. Third, even with spatially resolved NIRS, changes in skin blood flow influence the NIRS signal [24,25]. Although AVP decreases the skin blood flow [9], it was not quantified in the present study. Thus, the changes in NIRS signal between the skin blood flow and CBF could not be differentiated. Fourth, AVP was given 2 min before the positioning as its effect peaks within 1 to $2 \mathrm{~min}$ [9]. Hence, MAP in the presitting period was high, although its highest value $(140 \mathrm{mmHg})$ was still within the upper limit of autoregulation. If AVP was given along with the positioning, the high peaks could have been negated by BCP-induced hypotensive effects. Finally, NIRS recording differs with the use of different vasopressors. Phenylephrine and norepinephrine but not ephedrine reduces NIRS signals along with elevated MAP [24,25]. Different type of vasopressors in different groups in the present study may have affected the results. However, vasopressors used to treat hypotension in BCP were not different among the groups in the present study. 
In conclusion, AVP dose-dependently attenuates hypotension associated with BCP in patients undergoing shoulder surgery under general anesthesia. However, the use of AVP is associated with regional cerebral desaturation but notwith jugular venous desaturation on upright positioning.

\section{References}

1. Peruto CM, Ciccotti MG, Cohen SB. Shoulder arthroscopy positioning: lateral decubitus versus beach chair. Arthroscopy 2009; 25: 891-6.

2. Buhre W, Weyland A, Buhre K, Kazmaier S, Mursch K, Schmidt M, et al. Effects of the sitting position on the distribution of blood volume in patients undergoing neurosurgical procedures. Br J Anaesth 2000; 84: 354-7.

3. Pohl A, Cullen DJ. Cerebral ischemia during shoulder surgery in the upright position: a case series. J Clin Anesth 2005; 17: 463-9.

4. Drummond JC, Lee RR, Howell JP Jr. Focal cerebral ischemia after surgery in the "beach chair" position: the role of a congenital variation of circle of Willis anatomy. Anesth Analg 2012; 114: 1301-3.

5. Jeong H, Jeong S, Lim HJ, Lee J, Yoo KY. Cerebral oxygen saturation measured by near-infrared spectroscopy and jugular venous bulb oxygen saturation during arthroscopic shoulder surgery in beach chair position under sevoflurane-nitrous oxide or propofol-remifentanil anesthesia. Anesthesiology 2012; 116: 1047-56.

6. Trentman TL, Fassett SL, Thomas JK, Noble BN, Renfree KJ, Hattrup SJ. More hypotension in patients taking antihypertensives preoperatively during shoulder surgery in the beach chair position. Can J Anaesth 2011; 58: 993-1000.

7. Meng L, Cannesson M, Alexander BS, Yu Z, Kain ZN, Cerussi AE, et al. Effect of phenylephrine and ephedrine bolus treatment on cerebral oxygenation in anaesthetized patients. Br J Anaesth 2011; 107: 209-17.

8. Morelli A, Tritapepe L, Rocco M, Conti G, Orecchioni A, De Gaetano A, et al. Terlipressin versus norepinephrine to counteract anesthesiainduced hypotension in patients treated with renin-angiotensin system inhibitors: effects on systemic and regional hemodynamics. Anesthesiology 2005; 102: 12-9.

9. Delmas A, Leone M, Rousseau S, Albanese J, Martin C. Clinical review: Vasopressin and terlipressin in septic shock patients. Crit Care 2005; 9: $212-22$.

10. Lindner KH, Prengel AW, Pfenninger EG, Lindner IM, Strohmenger HU, Georgieff M, et al. Vasopressin improves vital organ blood flow during closed-chest cardiopulmonary resuscitation in pigs. Circulation 1995; 91: 215-21.

11. Dudkiewicz M, Proctor KG. Tissue oxygenation during management of cerebral perfusion pressure with phenylephrine or vasopressin. Crit Care Med 2008; 36: 2641-50.

12. Cho SY, Kim SJ, Jeong CW, Jeong CY, Chung SS, Lee J, et al. Under general anesthesia arginine vasopressin prevents hypotension but impairs cerebral oxygenation during arthroscopic shoulder surgery in the beach chair position. Anesth Analg 2013; 117: 1436-43.

13. Drummond JC, Hargens AR, Patel PM. Hydrostatic gradient is important: blood pressure should be corrected. APSF Newsletter $2009 ; 24: 6$.

14. Conti A, Iacopino DG, Fodale V, Micalizzi S, Penna O, Santamaria LB. Cerebral haemodynamic changes during propofol-remifentanil or sevoflurane anaesthesia: transcranial Doppler study under bispectral index monitoring. Br J Anaesth 2006; 97: $333-9$.

15. Fox J, Gelb AW, Enns J, Murkin JM, Farrar JK, Manninen PH. The responsiveness of cerebral blood flow to changes in arterial carbon dioxide is maintained during propofol-nitrous oxide anesthesia in humans. Anesthesiology 1992; 77: 453-6.

16. Kaisti KK, Långsjö JW, Aalto S, Oikonen V, Sipilä H, Teräs M, et al. Effects of sevoflurane, propofol, and adjunct nitrous oxide on regional cerebral blood flow, oxygen consumption, and blood volume in humans. Anesthesiology 2003; 99: 603-13.

17. Matta BF, Heath KJ, Tipping K, Summors AC. Direct cerebral vasodilatory effects of sevoflurane and isoflurane. Anesthesiology 1999; 91: 677-80.

18. Gopinath SP, Cormio M, Ziegler J, Raty S, Valadka A, Robertson CS. Intraoperative jugular desaturation during surgery for traumatic intracranial hematomas. Anesth Analg 1996; 83: 1014-21.

19. Samra SK, Dy EA, Welch K, Dorje P, Zelenock GB, Stanley JC. Evaluation of a cerebral oximeter as a monitor of cerebral ischemia during carotid endarterectomy. Anesthesiology 2000; 93: 964-70.

20. Bein B, Cavus E, Dörges V, Stadlbauer KH, Tonner PH, Steinfath M, et al. Arginine vasopressin reduces cerebral oxygenation and cerebral blood volume during intact circulation in swine---a near infrared spectroscopy study. Eur J Anaesthesiol 2005; 22: 62-6.

21. Fernández N, Martínez MA, García-Villalón AL, Monge L, Diéguez G. Cerebral vasoconstriction produced by vasopressin in conscious goats: role of vasopressin V(1) and V(2) receptors and nitric oxide. Br J Pharmacol 2001; 132: 1837-44.

22. Strebel SP, Kindler C, Bissonnette B, Tschaler G, Deanovic D. The impact of systemic vasoconstrictors on the cerebral circulation of anesthetized patients. Anesthesiology 1998; 89: 67-72.

23. Suzuki Y, Satoh S, Oyama H, Takayasu M, Shibuya M, Sugita K. Vasopressin mediated vasodilation of cerebral arteries. J Auton Nerv Syst 1994; 49 Suppl: S129-32.

24. Davie SN, Grocott HP. Impact of extracranial contamination on regional cerebral oxygen saturation: a comparison of three cerebral oximetry technologies. Anesthesiology 2012; 116: 834-40.

25. Sorensen H, Secher NH, Siebenmann C, Nielsen HB, Kohl-Bareis M, Lundby C, et al. Cutaneous vasoconstriction affects near-infrared 
spectroscopy determined cerebral oxygen saturation during administration of norepinephrine. Anesthesiology 2012; 117: 263-70.

26. Watzman HM, Kurth CD, Montenegro LM, Rome J, Steven JM, Nicolson SC. Arterial and venous contributions to near-infrared cerebral oximetry. Anesthesiology 2000; 93: 947-53.

27. Ogoh S, Sato K, Fisher JP, Seifert T, Overgaard M, Secher NH. The effect of phenylephrine on arterial and venous cerebral blood flow in healthy subjects. Clin Physiol Funct Imaging 2011; 31: 445-51.

28. Sorensen H, Rasmussen P, Sato K, Persson S, Olesen ND, Nielsen HB, et al. External carotid artery flow maintains near infrared spectroscopy-determined frontal lobe oxygenation during ephedrine administration. Br J Anaesth 2014; 113: 452-8.

29. Ogoh S, Sato K, Okazaki K, Miyamoto T, Secher F, Sorensen H, et al. A decrease in spatially resolved near-infrared spectroscopy-determined frontal lobe tissue oxygenation by phenylephrine reflects reduced skin blood flow. Anesth Analg 2014; 118: 823-9.

30. Treschan TA, Peters J. The vasopressin system: physiology and clinical strategies. Anesthesiology 2006; 105: 599-612. 